\title{
Spectroscopy and Femtosecond Dynamics of Excited-State Proton Transfer Induced Charge Transfer Reaction
}

\author{
Cheng-Chih Hsieh, Yi-Ming Cheng, Chia-Jung Hsu, Kew-Yu Chen, and Pi-Tai Chou* \\ Department of Chemistry, National Taiwan University, Taipei, 106, Taiwan, Republic of China
}

Received: May 13, 2008; Revised Manuscript Received: June 25, 2008

\begin{abstract}
Fluorescence spectroscopy and femtosecond relaxation dynamics of 2-\{[2-(2-hydroxyphenyl)benzo[d]oxazol-6yl]methylene $\}$ malononitrile (diCN-HBO) and 2-\{[2-(2-hydroxyphenyl)benzo[d]thiazol-6-yl]methylene $\}$ malononitrile (diCN-HBT) are studied to probe the excited-state proton transfer (ESPT) coupled charge transfer (ESCT) reaction. Unlike most of the ESPT/ESCT systems previously designed, in which ESCT takes place prior to ESPT, both diCN-HBO and diCN-HBT undergo ESPT, concomitantly accompanied with the charge transfer process, such that the ESPT reaction dynamics are directly coupled with solvent polarization effects. The long-range solvent polarization interactions result in a solvent-induced barrier that affects the overall proton transfer reaction rate. In cyclohexane, the rate constant of ESPT of diCN-HBO is measured to be $1.1 \mathrm{ps}\left(9.1 \times 10^{11} \mathrm{~s}^{-1}\right)$, which is apparently slower than that of $150 \mathrm{fs}$ for the parent molecule 2-(2'-hydroxyphenyl)benzoxazole (HBO). Upon increasing solvent polarity to, for example, $\mathrm{CH}_{3} \mathrm{CN}$, the rate of ESPT is increased to $300 \mathrm{fs}\left(3.3 \times 10^{12} \mathrm{~s}^{-1}\right)$. The results are rationalized by the stabilization of proton transfer tautomer, which possesses a large degree of charge transfer character via an increase of the solvent polarity, such that the corresponding solvent-induced barrier is reduced. We thus demonstrate a prototypical system in which the photon-induced nuclear motion (proton transfer) is directly coupled with solvent polarization and the corresponding mechanism is reminiscent of that applied in an electron transfer process.
\end{abstract}

\section{Introduction}

Because of its fundamental importance in chemical reactions, the excited-state proton transfer (ESPT) reaction has attracted intensive interest. ${ }^{1,2}$ Among various experimental approaches, one important issue of current interest is the ESPT coupled excited-state charge transfer (ESCT) reaction. A conceptually designed ESCT/ESPT system (PC) is depicted in Scheme 1, in which $\mathrm{D}$ and $\mathrm{A}$ denote the electron donor and acceptor, respectively. In most cases, D and A are separated by a chromophore (represented by a benzenelike structure), and their relative positions are suited for the charge transfer reaction via, for example, $\pi$ electron delocalization in the excited state. Symbol H denotes a hydroxyl (or amino) hydrogen, which forms an intramolecular hydrogen bond (dashed line) with $\mathrm{A}$ in most designed systems. ${ }^{3-7}$

On one hand, electronically exciting PC to PC* (* denotes the electronically excited state) may cause charge transfer, forming a charge transfer species $\mathrm{CT}^{*}$. On the other hand, the hydrogen-bonded $\mathrm{H}$ atom may act as a strong photoacid, such that proton transfer takes place, resulting in a proton transfer tautomer denoted by $\mathrm{PT}^{*}$ (see Scheme 1 ). Thus, depending on the reaction time domain, studies of ESCT vs ESPT can be classified into two categories: (A) For the case that the rate of ESCT is faster than that of ESPT, following PC* $\rightarrow \mathrm{CT}^{*}$ charge transfer, the $\mathrm{CT}^{*} \rightarrow \mathrm{CPT}^{*}$ proton transfer reaction then takes place. (B) For the case that ESPT takes place prior to ESCT, the overall reaction may be described as a $\mathrm{PC}^{*} \rightarrow \mathrm{PT}^{*}$ proton transfer, followed by a $\mathrm{PT}^{*} \rightarrow \mathrm{CPT}^{*}$ charge transfer process.

As for case A, because of a large charge separation between $\mathrm{D}$ and $\mathrm{A}$, the initially prepared $\mathrm{CT}^{*}$ should be subject to a great change of the dipole moment vs that of the ground state PC. Moreover, if $\mathrm{CT}^{*}$ possesses a large difference in dipole moment

* To whom correspondence should be addressed. Tel: +886-2-33663894. Fax: +886-2-23695208. E-mail: chop@ntu.edu.tw. from that of the final proton transfer tautomer, $\mathrm{CPT}^{*}$, the equilibrium polarizations between $\mathrm{CT}^{*}$ and $\mathrm{CPT}^{*}$ should be far separated. Similarly, a large difference in dipole moment is also expected between $\mathrm{PT}^{*}$ and $\mathrm{CPT} *$ in case $\mathrm{B}$. Because the dipolar changes in solute are coupled to solvent polarization effects, the relative energetics between $\mathrm{CT}^{*}$ and $\mathrm{CPT}^{*}$ in case $\mathrm{A}$ or between $\mathrm{PT}^{*}$ and $\mathrm{CPT}^{*}$ in case $\mathrm{B}$ are expected to be a function of solvent polarization coordinate. Thus, the long-range solvent polarization interactions may result in a solvent-induced barrier channeling into the overall reaction.

On the above basis, research regarding solvent polarity influencing ESPT has made vast progress. ${ }^{3-7}$ Many intriguing ESCT/ESPT systems have been designed and intensively investigated during the past few years. Representative examples include $N, N$-dialkylamino-3-hydroxyflavones ${ }^{4,5}$ and 2-(2'-hydroxy- $4^{\prime}$-dietheylaminophenyl)benzothiazole, ${ }^{6}$ etc. (see Scheme 2 ), in which the $N, N$-dialkyl group is commonly exploited as an electron donor, while the carbonyl oxygen or the nitrogen group serves as an electron acceptor. Studies so far have shown that most designed systems can be ascribed to case A. Using 2-hydroxy-4-(di-p-tolyl-amino)benzaldehyde ${ }^{7}$ as an example, the early reaction dynamics can be described by an ultrafast ESCT $(<150 \mathrm{fs}$ ) prior to ESPT (see Scheme 3). Such an ESCT process is essentially adiabatic, that is, an optical electron transfer process, and can be rationalized by a strong coupling between donor and acceptor moieties through the $\pi$ electron conjugation such that the electronic coupling matrix is much larger than that of the Marcus type of the weak coupling electron transfer process. ${ }^{8}$ For this case, following ultrafast ESCT, it is always found that ESPT takes place and its rate is complicated by the competitive solvation relaxation process, that is, the $\mathrm{CT}^{*} \rightarrow$ $\mathrm{CT}_{\mathrm{eq}}$ * process (subscript eq denotes the solvent equilibrated state). After reaching the solvent equilibration, because of the difference in equilibrium polarization between $\mathrm{CT}_{\mathrm{eq}}{ }^{*}$ and 


\section{SCHEME 1: Generalized ESCT/ESPT System and Its Possible Reaction Patterns ${ }^{a}$}

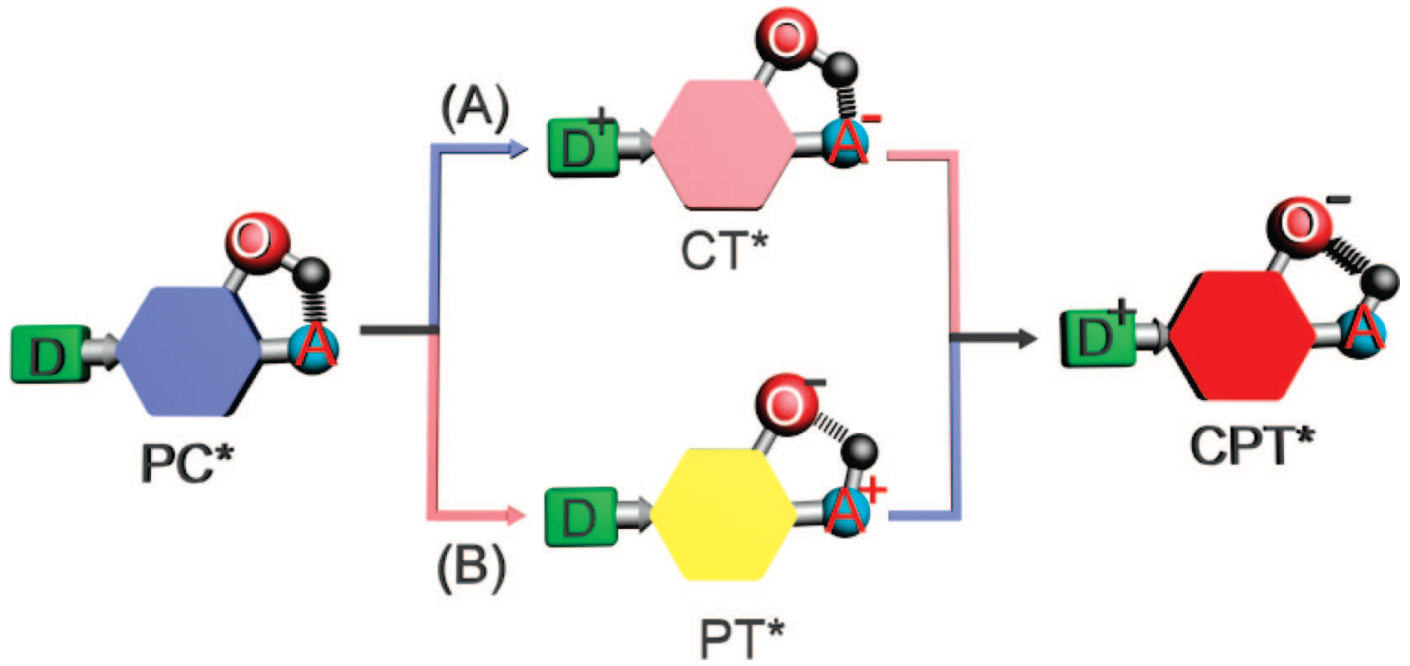

${ }^{a}$ See the text for the notation of each species.

\section{SCHEME 2: Molecular Structures of Some Representative ESCT/ESPT Compounds}<smiles>[R20]c1ccc(-c2oc3ccccc3c(=O)c2O[CH])cc1</smiles>

$N, N$-dialkylamino-3-hydroxyflavone<smiles>Cc1ccc(N(c2ccc(C)cc2)c2ccc3c(c2)O[CH]OC3)cc1</smiles>

2-hydroxy-4-(di-p-tolyl-amino)benzaldehyde<smiles>CN(C)c1ccc2c(c1)O[CH][n+]1c-2sc2ccccc21</smiles>

2-(2'-hydroxy-4'-dietheylaminophenyl)benzothiazole

$\mathrm{CPT}_{\mathrm{eq}} *$, the $\mathrm{CT}_{\mathrm{eq}} * \rightarrow \mathrm{CPT}_{\mathrm{eq}} *$ proton transfer reaction is associated with a solvent-induced barrier (see Scheme 3 ).

The above experimental progress has drawn fundamental importance because solvent polarity plays a key role and channels into the proton transfer dynamics, the mechanism of which has been intensively developed theoretically during the past decade. ${ }^{9}$ Unfortunately, for most experimental model systems applied up to this stage, the ESPT/ESCT dynamics are ascribed to case A and are complicated by the competitive solvent relaxation vs ESPT, such that the study of early ESCT/ ESPT reaction dynamics is limited by the rate of solvent relaxation. Thus, it is of great fundamental interest to seek an ideal system to probe the ESPT/ESCT coupling reaction. To our viewpoint, an ideal case in point stems from case B, for which a molecule is designed such that it undergoes ESPT prior to the ESCT reaction. To achieve this goal, 2-\{[2-(2-hydroxyphenyl)benzo[d]oxazol-6-yl]methylene $\}$ malononitrile (diCN-
HBO $)^{10}$ and 2-\{[2-(2-hydroxyphenyl)benzo[d]thiazol-6yl]methylene \}malononitrile (diCN-HBT) (see Scheme 4) were synthesized. As elaborated in the following sections, we then demonstrate that diCN-HBO and diCN-HBT undergo ESPT concomitantly associated with charge transfer. The results and discussion render a prototype to probe the nuclear motion (proton transfer) directly coupled with electron transfer.

\section{Experimental Section}

Synthesis. Syntheses of diCN-HBO were performed according to the literature. ${ }^{10}{ }^{1} \mathrm{H} \mathrm{NMR}\left(400 \mathrm{MHz}, \mathrm{CDCl}_{3}\right.$, in ppm): $11.10(\mathrm{~s}, 1 \mathrm{H}), 8.38(\mathrm{~s}, 1 \mathrm{H}), 8.08(\mathrm{~d}, J=8.0 \mathrm{~Hz}, 1 \mathrm{H}), 7.81-7.88$ $(\mathrm{m}, 3 \mathrm{H}), 7.54(\mathrm{t}, J=7.8 \mathrm{~Hz}, 1 \mathrm{H}), 7.17(\mathrm{~d}, J=8.4 \mathrm{~Hz}, 1 \mathrm{H})$, $7.08(\mathrm{t}, J=7.6 \mathrm{~Hz}, 1 \mathrm{H}) .{ }^{13} \mathrm{C} \mathrm{NMR}\left(125 \mathrm{MHz}, \mathrm{CDCl}_{3}\right.$, in ppm): 166.64, 159.48, 158.80, 149.27, 145.40, 135.18, 129.55, 127.90, 127.66, 120.09, 119.99, 117.81, 113.64, 112.69, 111.82, 109.44, 82.24 . 


\section{SCHEME 3: Relaxation Processes for Case (A) ESCT/ ESPT Systems Demonstrated by para- $N, N$-Dialkylaminosalicylaldehyde ${ }^{7}$}

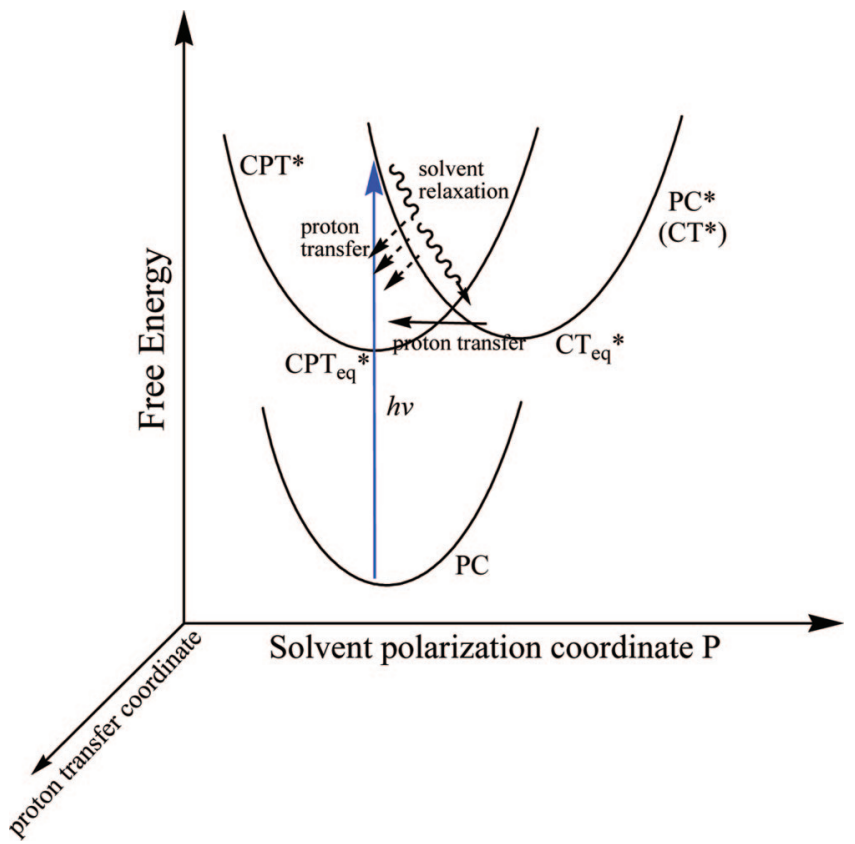

SCHEME 4: Proposed ESPT Reaction for HBO (HBT) and ESPT/ESCT Coupled Reaction for diCN-HBO (diCN-HBT)
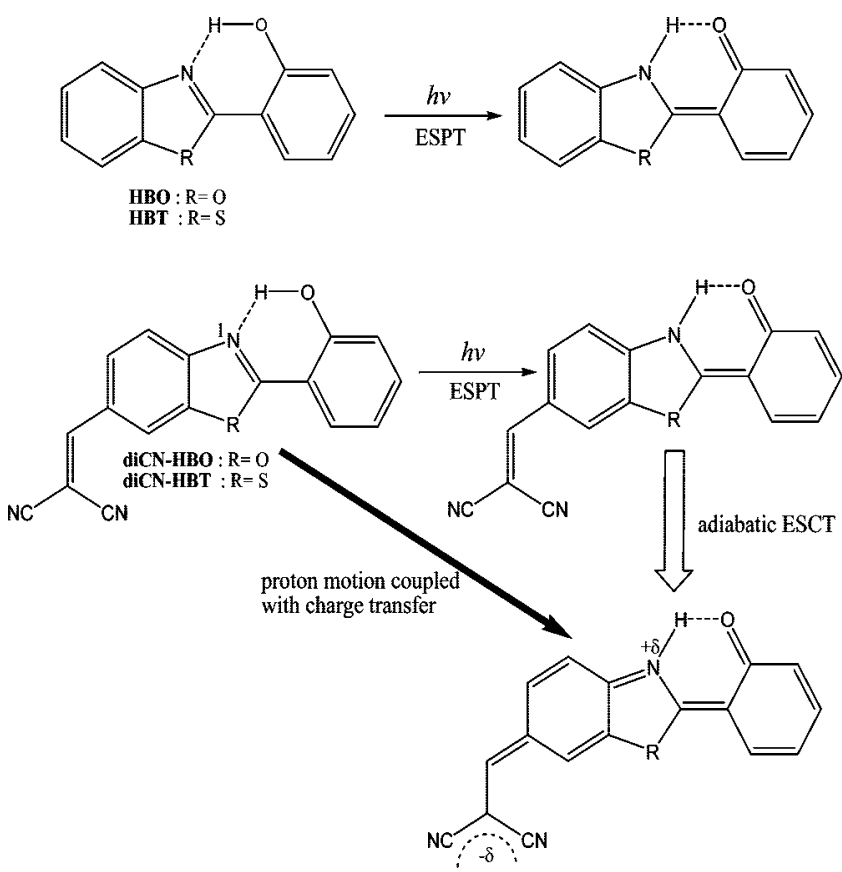

The synthesis of diCN-HBT (6) was performed according to a synthetic route depicted in Scheme $5 .{ }^{1} \mathrm{H}$ and ${ }^{13} \mathrm{C}$ spectra were obtained on a Bruker AMX-400 spectrometer. Mass spectra were carried out on a VG70-250S spectrometer.

2-(6-Methylbenzo[d]thiazol-2-yl)phenol (1). 2-Amino-5methylbenzenethiol ${ }^{11}(3.0 \mathrm{~g}, 21.5 \mathrm{mmol})$ and 2-hydroxybenzaldehyde $(2.6 \mathrm{~g}, 21.5 \mathrm{mmol})$ were added to $80 \mathrm{~mL}$ of acetic acid. After the mixture was stirred for $10 \mathrm{~min}$ at room temperature, lead(IV) acetate $(9.5 \mathrm{~g}, 21.5 \mathrm{mmol})$ was added to the mixture. The reaction mixture was stirred for $30 \mathrm{~min}$ and gently boiled for an additional $30 \mathrm{~min}$. After it was cooled, the mixture was poured into the cold water and was neutralized with aqueous $\mathrm{NaOH}$ solution. The precipitate was filtered and dissolved in excess $\mathrm{CHCl}_{3}$ and dried with anhydrous $\mathrm{MgSO}_{4}$. After the solvent was removed, the crude product was purified by silica gel column chromatography with eluent ethyl acetate/ $n$-hexane (1/10) to afford 1 (2.8 g, 54\%). ${ }^{1} \mathrm{H}$ NMR $\left(\mathrm{CDCl}_{3}\right.$, ppm): $12.52(\mathrm{~s}, 1 \mathrm{H}), 7.89(\mathrm{~d}, J=8.3 \mathrm{~Hz}, 1 \mathrm{H}), 7.67-7.70(\mathrm{~m}$, 2H), $7.40(\mathrm{t}, J=8.6 \mathrm{~Hz}, 1 \mathrm{H}), 7.33(\mathrm{~d}, J=8.3 \mathrm{~Hz}, 1 \mathrm{H}), 7.12$ $(\mathrm{d}, J=8.3, \mathrm{~Hz}, 1 \mathrm{H}), 6.98(\mathrm{t}, J=7.5 \mathrm{~Hz}, 1 \mathrm{H}), 2.52(\mathrm{~s}, 3 \mathrm{H})$. MS (EI, $70 \mathrm{eV}): \mathrm{m} / \mathrm{z}$ (relative intensity) $241\left(\mathrm{M}^{+}, 42\right), 231$ (100). HRMS calcd for $\mathrm{C}_{14} \mathrm{H}_{11} \mathrm{ONS}$, 241.0561; found, 241.0558.

2-\{6-(Bromomethyl)benzo $[d]$ thiazol-2-yl $\}$ phenyl Acetate (3). In $100 \mathrm{~mL}$ of acetic anhydride, 2-(6-methylbenzo[ $d]$ thiazol2-yl)phenol ( $2.0 \mathrm{~g}, 8.3 \mathrm{mmol})$ was dissolved and was heated to $120{ }^{\circ} \mathrm{C}$ with stirring for $12 \mathrm{~h}$. After the solvent was distilled off under reduced pressure, 2-(6-methylbenzo $[d]$ thiazol-2yl)phenyl acetate (2) and $N$-bromosuccinimide $(1.4 \mathrm{~g}, 7.8 \mathrm{mmol})$ were dissolved in $60 \mathrm{~mL}$ of $\mathrm{CCl}_{4}$, and $14 \mathrm{mg}(1 \mathrm{~mol} \%)$ of $2,2^{\prime}$-azobisisobutyronitrile (AIBN) was added. The mixture was slowly heated to $80^{\circ} \mathrm{C}$ with stirring for $2 \mathrm{~h}$. After it was cooled, the mixture was poured into cold water, extracted with $\mathrm{CHCl}_{3}$, and dried with anhydrous $\mathrm{MgSO}_{4}$. After the solvent was removed, the crude product was purified by silica gel column chromatography with eluent ethyl acetate/n-hexane (1/10) to afford (3) $(1.9 \mathrm{~g}, 63 \%) .{ }^{1} \mathrm{H}$ NMR $\left(\mathrm{CDCl}_{3}, \mathrm{ppm}\right): 8.32$ (dd, $J=$ $7.8,1.3 \mathrm{~Hz}, 1 \mathrm{H}), 8.06(\mathrm{~d}, J=8.5 \mathrm{~Hz}, 1 \mathrm{H}), 7.91(\mathrm{~s}, 1 \mathrm{H})$, $7.51-7.55(\mathrm{~m}, 2 \mathrm{H}), 7.43(\mathrm{t}, J=7.8 \mathrm{~Hz}, 1 \mathrm{H}), 7.28(\mathrm{~d}, J=7.8$ $\mathrm{Hz}, 1 \mathrm{H}), 4.66$ (s, 2H), 2.48 (s, 3H). MS (EI, $70 \mathrm{eV}$ ): $\mathrm{m} / z$ (relative intensity) $361\left(\mathrm{M}^{+}, 20\right), 319$ (100). HRMS calcd for $\mathrm{C}_{16} \mathrm{H}_{12} \mathrm{O}_{2} \mathrm{NBrS}$, 360.9772; found, 360.9765 .

2-(2-Hydroxyphenyl)benzo[d]thiazole-6-carbaldehyde (5). Hexamethylenetetramine (HMTA) $(1.2 \mathrm{~g}, 8.6 \mathrm{mmol}$ ) was added to a solution of 2-\{6-(bromomethyl)benzo[ $d]$ thiazol-2-yl $\}$ phenyl acetate $(1.5 \mathrm{~g}, 4.1 \mathrm{mmol})$ in $60 \mathrm{~mL}$ of $\mathrm{CHCl}_{3}$. The mixture was refluxed for $12 \mathrm{~h}$. After the mixture was cooled, the residual precipitate was filtered and dried. Next, to $15 \mathrm{~mL}$ of glacial acetic acid and $15 \mathrm{~mL}$ of water was added dried salt, and the mixture was refluxed for $2 \mathrm{~h}$. After it was cooled, the mixture was neutralized with aqueous $\mathrm{NaOH}$ solution and was extracted with $\mathrm{CHCl}_{3}$. The organic layer was dried with anhydrous $\mathrm{MgSO}_{4}$ and evaporated. The mixture of $\mathbf{4}$ and $\mathbf{5}$ was dissolved in a suspension of $0.3 \mathrm{~g}$ of $\mathrm{KOH}$ in $50 \mathrm{~mL}$ of $\mathrm{CH}_{2} \mathrm{Cl}_{2}$. The mixture was gently boiled for $6 \mathrm{~h}$. After it was cooled, the solution was poured into water and neutralized with aqueous $\mathrm{HCl}$ solution. The mixture was extracted with $\mathrm{CH}_{2} \mathrm{Cl}_{2}$ and dried with anhydrous $\mathrm{MgSO}_{4}$. After the solvent was removed, the crude product was purified by silica gel column chromatography with eluent ethylacetate $/ n$-hexane (1/4) to afford $5(0.50 \mathrm{~g}, 47 \%)$. ${ }^{1} \mathrm{H}$ NMR $\left(\mathrm{CDCl}_{3}, \mathrm{ppm}\right): 12.26(\mathrm{~s}, 1 \mathrm{H}), 10.11(\mathrm{~s}, 1 \mathrm{H}), 8.44(\mathrm{~s}$, $1 \mathrm{H}), 8.11(\mathrm{~d}, J=8.4 \mathrm{~Hz}, 1 \mathrm{H}), 8.03(\mathrm{~d}, J=8.4 \mathrm{~Hz}, 1 \mathrm{H}), 7.73$ $(\mathrm{d}, J=8.2 \mathrm{~Hz}, 1 \mathrm{H}), 7.44(\mathrm{t}, J=7.3 \mathrm{~Hz}, 1 \mathrm{H}), 7.12(\mathrm{~d}, J=8.2$ $\mathrm{Hz}, 1 \mathrm{H}), 7.06(\mathrm{t}, J=7.4 \mathrm{~Hz}, 1 \mathrm{H}) .{ }^{13} \mathrm{C}$ NMR $\left(100 \mathrm{MHz}, \mathrm{CDCl}_{3}\right.$, ppm): 190.72, 173.52, 158.19, 155.77, 133.79, 133.53, 133.20, 128.73, 127.84, 123.95, 122.51, 119.81, 118.16. 116.34. MS (EI, $70 \mathrm{eV}): \mathrm{m} / \mathrm{z}$ (relative intensity) $255\left(\mathrm{M}^{+}, 100\right)$. HRMS calcd for $\mathrm{C}_{14} \mathrm{H}_{9} \mathrm{O}_{2} \mathrm{NS}$, 255.0354; found, 255.0356 .

diCN-HBT (6). 2-(2-Hydroxyphenyl)benzo[d] thiazole-6-carbaldehyde $(0.15 \mathrm{~g}, 0.59 \mathrm{mmol})$ was resolved in a mixture of 20 $\mathrm{mL}$ of THF and $20 \mathrm{~mL}$ of $\mathrm{MeOH}$. Then, malononitrile $(0.19 \mathrm{~g}$, $2.88 \mathrm{mmol}$ ) and two drops of piperidine were added to the mixture and stirred for $2 \mathrm{~h}$ at $45^{\circ} \mathrm{C}$. After the solvent was removed under vacuum, the mixture was extracted with $\mathrm{CHCl}_{3}$ and washed with water. The organic layer was dried with anhydrous $\mathrm{MgSO}_{4}$ and evaporated. The product was purified by silica gel column chromatography with eluent ethyl acetate/ 
SCHEME 5: Synthetic Scheme of diCN-HBT
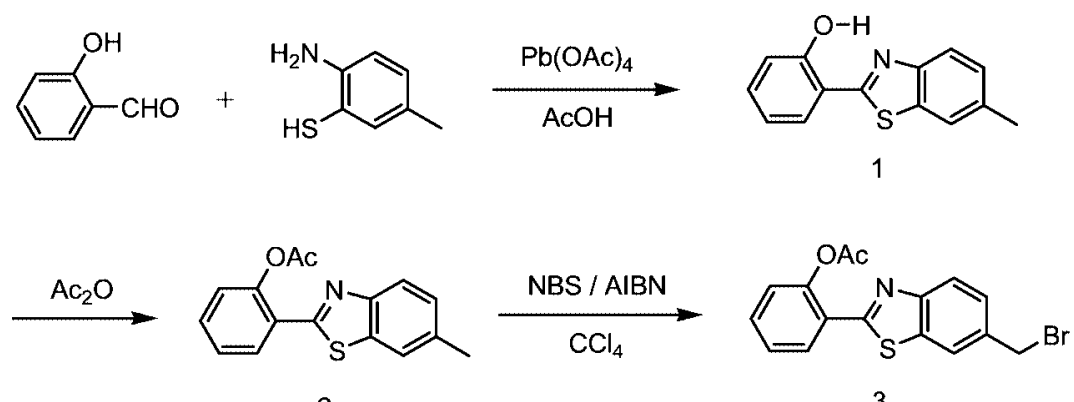

2

3

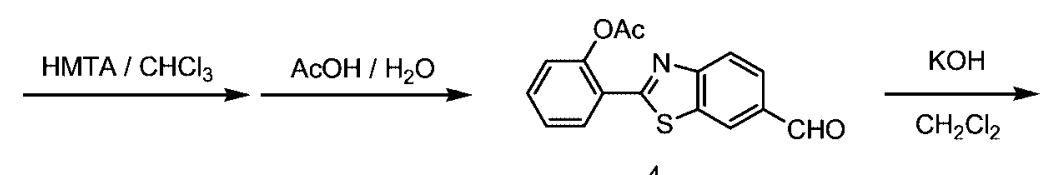

4

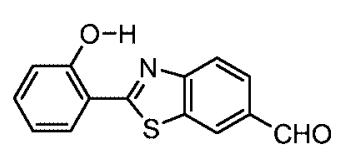

5

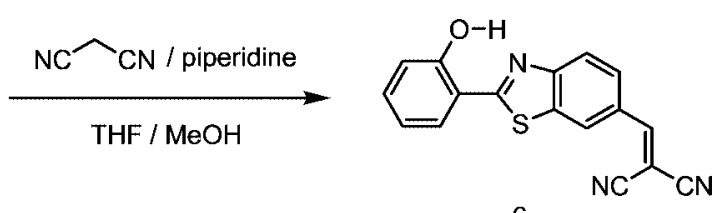

6 $n$-hexane (1/4) to afford $6(0.13 \mathrm{~g}, 73 \%) .{ }^{1} \mathrm{H} \mathrm{NMR}\left(\mathrm{CDCl}_{3}\right.$, ppm): 12.13 (s, 1H), $8.54(\mathrm{~s}, 1 \mathrm{H}), 8.12(\mathrm{~d}, J=8.6 \mathrm{~Hz}, 1 \mathrm{H})$, $8.05(\mathrm{~d}, J=8.6 \mathrm{~Hz}, 1 \mathrm{H}), 7.92(\mathrm{~s}, 1 \mathrm{H}), 7.77(\mathrm{~d}, J=7.4 \mathrm{~Hz}$, $1 \mathrm{H}), 7.48$ (t, $J=8.1 \mathrm{~Hz}, 1 \mathrm{H}), 7.12(\mathrm{~d}, J=8.3 \mathrm{~Hz}, 1 \mathrm{H}), 7.03$ $(\mathrm{t}, J=7.4 \mathrm{~Hz}, 1 \mathrm{H}) .{ }^{13} \mathrm{C} \mathrm{NMR}\left(100 \mathrm{MHz}, \mathrm{CDCl}_{3}, \mathrm{ppm}\right): 158.75$, $158.32,155.54,148.59,134.13,133.89,129.18,128.90,128.10$, 124.57, 122.73, 119.89, 118.02. 116.20, 113.82, 112.81, 82.41. MS (EI, $70 \mathrm{eV}): \mathrm{m} / \mathrm{z}$ (relative intensity) $303\left(\mathrm{M}^{+}, 100\right)$. HRMS calcd for $\mathrm{C}_{17} \mathrm{H}_{9} \mathrm{~N}_{3} \mathrm{OS}$, 303.0466; found, 303.0469.

The solvents used in the spectroscopic and dynamic measurements were of spectragrade quality (Merck Inc.) and were used right after received. Benzene and acetonitrile showed traces of fluorescence impurities and were fractionally distilled prior to use.

Measurements. Steady-state absorption and emission spectra were recorded by a Hitachi (U-3310) spectrophotometer and an Edinburgh (FS920) fluorimeter, respectively. Nanosecond-picosecond lifetime studies were performed with an Edinburgh OB 900-L time-correlated single photon counting system coupled with a femtosecond Ti-Sapphire oscillator $(82 \mathrm{MHz}$, Spectra Physics). The fundamental pulse was used to produce second harmonics (375-425 nm) as an excitation source. For measuring the extremely weak tautomer (i.e., keto) emission of diCN-HBO (or diCN-HBT) in $\mathrm{CH}_{3} \mathrm{CN}$, the laser (355 nm, third harmonic of $\mathrm{Nd}: \mathrm{YAG}$ ) induced fluorescence was collected at a right angle with respect to the excitation beam, focused to a monochromator (Acton, SP2300i), and then detected by a highly sensitive intensified charge-coupled detector (ICCD, Princeton Instrument, PI-MAX camera). The laser scattering was rejected by a combination of color and holographic filters.

The fluorescence upconversion measurements were performed with a previously reported femtosecond optically gated system. ${ }^{6}$ The upconverted signal was then separated by an F/4.9 $(f=$ $380 \mathrm{~mm}$ ) monochromator and detected via a photon counting PMT (R1527P, Hamamatsu). The cross-correlation between SH and the fundamental had a full width at half-maximum (fwhm) of $\sim 150 \mathrm{fs}$, which was chosen as a response function of the system.

\section{Results}

Design Strategy. As depicted in Scheme 4, for both diCN$\mathrm{HBO}$ and diCN-HBT, the lone pair electrons of the benzo nitrogen atom (N1, see Scheme 4) are intrinsically involved in the $\pi$ electron resonance to establish the aromaticity, such that its electron-donating strength, as compared with those of alkyl and aryl amines, is negligibly weak. Thus, upon Franck-Condon excitation of diCN-HBO (or diCN-HBT), the degree of charge transfer should be negligible. On the other hand, similar to their parent molecules such as 2-(2'-hydroxyphenyl)benzoxazole $(\mathrm{HBO})^{12}$ and 2-(2'-hydroxyphenyl)benzothiazole (HBT), ${ }^{13}$ ESPT is expected to take place from the hydroxyl proton to the N1 nitrogen, resulting in a proton transfer tautomer, that is, a keto form (see Scheme 4). Once forming the proton transfer tautomer, the N1 nitrogen atom becomes the secondary alkyl amino nitrogen and thus should act as a good electron donor. Moreover, because its para-position is strategically designed by anchoring a strong electron-withdrawing group, that is, malononitrile, charge transfer is thus anticipated for both diCN-HBO and diCN-HBT. Such a charge transfer process occurs through the delocalization of $\pi$ conjugation and is considered to be an adiabatic type of reaction. In other words, electron transfer should proceed simultaneously every moment ESPT takes place. One may thus view the overall reaction as a photon-induced proton transfer (a nuclear motion) coupled with a large charge separation due to the simultaneous electron transfer process, rendering an ideal system to study the role of solvent polarity in the proton transfer reaction. It is noted that Park and coworkers ${ }^{10}$ have reported the synthesis and steady-state luminescence properties for diCN-HBO, whereas the ESPT/ESCT coupled reaction dynamics have not yet been explored.

Steady State Approach. Figure 1 depicts steady state absorption and emission spectra of diCN-HBO in various solvents. In cyclohexane, the $\mathrm{S}_{0} \rightarrow \mathrm{S}_{1}\left(\pi \pi^{*}\right)$ transition of diCNHBO exhibits a maximum absorbance at $376 \mathrm{~nm}$ with an extinction coefficient of $\sim 2 \times 10^{4} \mathrm{M}^{-1} \mathrm{~cm}^{-1}$. The fluorescence spectrum of diCN-HBO in cyclohexane shows a weak normal 


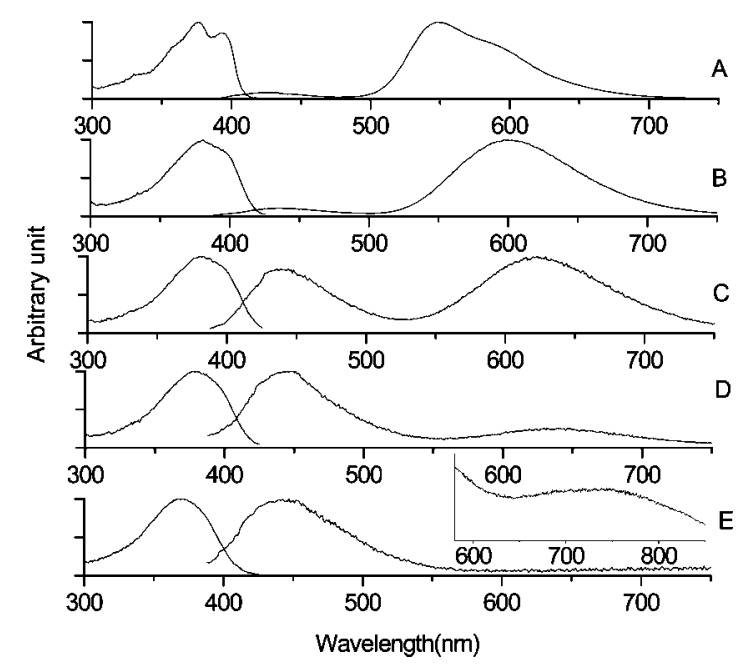

Figure 1. Static absorption and fluorescence spectra of diCN-HBO at $298 \mathrm{~K}$ in (A) cyclohexane, (B) benzene, (C) chloroform, (D) dichloromethane, and (E) acetonitrile; the inserted small graph was generated using ICCD as a detector.

Stokes shifted band (the $F_{1}$ band) maximized at $435 \mathrm{~nm}$ and large Stokes shifted band (the $\mathrm{F}_{2}$ band) maximized at $\sim 550 \mathrm{~nm}$. These steady-state results are essentially in agreement with a previous report. ${ }^{10}$ Upon monitoring throughout the two emission bands, the identical excitation spectra eliminate the possible existence of diCN-HBO isomer(s) as well as any unwanted emission originating from trace impurity. It is thus reasonable to assign the $435 \mathrm{~nm}$ band as the fluorescence from the enol $\left(\mathrm{N}^{*}\right)$ emission, while the $550 \mathrm{~nm}$ band is ascribed to the keto ( $\left.\mathrm{T}^{*}\right)$ emission resulting from the proton transfer reaction. The total quantum yield $\Phi$, that is, the yield of normal plus tautomer emission, is determined to be 0.13 (Table 1). Upon varying the solvents, while the absorption spectral feature reveals only slight solvent dependence, a remarkable solvent polarity-dependent emission property is observed. As shown in Figure 1, despite negligible spectral changes on the enol emission, the peak wavelength of proton transfer tautomer emission (i.e., the keto emission) of diCN-HBO shows drastic bathochromic shift upon increasing the solvent polarity, being shifted from $590 \mathrm{~nm}$ in benzene to as long as $750 \mathrm{~nm}$ in $\mathrm{CH}_{3} \mathrm{CN}$. In parallel, the quantum yield of the integrated dual emission decreases from 0.03 in benzene to $6 \times 10^{-4}$ in $\mathrm{CH}_{3} \mathrm{CN}$. In fact, a conventional fluorimeter could barely resolve the keto emission in $\mathrm{CH}_{3} \mathrm{CN}$. Alternatively, a laser-induced fluorescence technique coupled with a red-sensitive intensified charge-coupled detector (see the Experimental Section) had to be applied to resolve this rather weak keto emission in $\mathrm{CH}_{3} \mathrm{CN}$ (see the inset of Figure 1). The steady-state dual emission indirectly implies the existence of a non-negligible barrier associated with the ESPT process in diCN-HBO.

Similar solvent polarity-dependent emission properties are observed in diCN-HBT, for which the keto emission of diCNHBT undergoes a significant red shift from $575 \mathrm{~nm}$ in cyclohexane to $\sim 730 \mathrm{~nm}$ in $\mathrm{CH}_{3} \mathrm{CN}$, while the enol emission is nearly solvent-independent, being maximized at $450 \mathrm{~nm}$. Nevertheless, subtle differences in the steady-state emission can be seen between diCN-HBT and diCN-HBO. The ratio of emission intensity for enol vs keto species is significantly reduced in diCN-HBT. For example, in cyclohexane, which is considered to be the least perturbing solvent, enol emission of diCN-HBT could not be resolved with the steady-state approach, while appreciable enol emission was resolved in the case of diCN-HBO. In fact, except in $\mathrm{CH}_{3} \mathrm{CN}$, the enol vs keto emission ratio for diCN-HBT is rather small in all polar, aprotic solvents, the result of which is in sharp contrast to that of diCN-HBO (cf. Figures 1 and 2). On one hand, the sulfur atom in diCNHBT is considered to be a stronger electron-donating group than that of the oxygen atom in diCN-HBT. Thus, through $\mathrm{S} \rightarrow \mathrm{N}(1)$ [cf. $\mathrm{O} \rightarrow \mathrm{N}(1)$ in diCN-HBO] partial charge delocalization, the $\mathrm{N}(1)$ nitrogen in diCN-HBT is expected to be more basic than that in diCN-HBO, rendering a stronger intramolecular hydrogen bond in diCN-HBT and hence a faster rate of ESPT. On the other hand, it may indicate that solvent polarity plays a minor role in view of ESPT/ESCT coupled reaction for diCN-HBT due to its lesser charge transfer property in the proton transfer tautomer form. As a result, the dynamics of ESPT in diCNHBT are expected to be similar to its parent molecule HBT. It has been well-established that ESPT for HBT is essentially barrierless and that its rate constant is $160 \pm 20 \mathrm{fs}$, which is nearly independent of the solvent polarity. ${ }^{13 \mathrm{~b}}$ Further resolution of this issue relies on the results elaborated in the following sections.

The solvent polarity-dependent keto emission can be expressed quantitatively according to the theory derived from dielectric polarization, specifying that the spectral shifts of the fluorescence upon increasing the solvent polarity depend on the difference in permanent dipole moments between ground $\left(\vec{\mu}_{g}\right)$ and excited $\left(\vec{\mu}_{e}\right)$ state. The changes of dipole moment in magnitude between ground and excited states, that is, $\Delta \mu=\mid \vec{\mu}_{e}$ $-\vec{\mu}_{g}$ l, can be estimated by the Lippert-Mataga equation and expressed as:

$$
\bar{v}_{a}-\bar{v}_{f}=\frac{2}{h c}\left(\mu_{e}-\mu_{g}\right)^{2} a_{0}{ }^{-3} \Delta f+\text { const. }
$$

where $a_{0}$ denotes the cavity radius in which the solute resides, estimated to be $6.9 \AA$ via the Hartree-Fock theories with 6-31G( $\left(\mathrm{d}^{\prime}, \mathrm{p}^{\prime}\right)$ basis, $\bar{v}_{a}-\bar{v}_{f}$ is the Stokes shift of the absorption and emission peak maximum, and $\Delta f$ is the orientation polarizability defined as:

$$
\Delta f=f(\varepsilon)-f\left(n^{2}\right)=\frac{\varepsilon-1}{2 \varepsilon+1}-\frac{n^{2}-1}{2 n^{2}+1}
$$

The plot of the Stokes shift $\bar{v}_{a}-\bar{v}_{f}$ as a function of $\Delta f$ is sufficiently linear for both diCN-HBO and diCN-HBT (see Figure 3). Accordingly, $\Delta \mu=\left|\vec{\mu}_{e}-\vec{\mu}_{g}\right|$ was deduced to be 21 and $16 \mathrm{D}$ for diCN-HBO and diCN-HBT, respectively, ascertaining the electron transfer origin of the proton transfer (keto) emission band for both compounds. Moreover, the results also imply a smaller degree of charge transfer for the keto form in diCN-HBT. Accordingly, as compared to diCN-HBO, the corresponding ESPT in diCN-HBT being subject to less solvent polarity perturbation is justified.

Relaxation Dynamics. The above steady-state solvent polarity-dependent keto emission is in sharp contrast to most ESPT/ ESCT systems studied so far. ${ }^{4-7}$ For those systems reported, the proton transfer tautomer emission peak wavelength commonly does not reveal solvent polarity dependence. Instead, it is the normal emission that shows great solvent polarity dependence, being red-shifted upon an increase in the solvent polarity. For previously designed ESPT/ESCT coupled systems, this can be rationalized by the occurrence of optical electron transfer in the excited normal species, creating gigantic dipolar changes. Thus, charge transfer occurs simultaneously upon Franck-Condon excitation. Once charge transfer species are formed, solvent relaxation promptly takes place, and its rate is either competitive or even prior to the ESPT process (see Scheme 3), complicating the early relaxation dynamics. In 
TABLE 1: Photophysical Properties of diCN-HBO and diCN-HBT in Various Solvents ${ }^{a}$

\begin{tabular}{|c|c|c|}
\hline & emission (nm) & relaxation dynamics $(\mathrm{ps})^{b}$ \\
\hline \multicolumn{3}{|l|}{ diCN-HBO } \\
\hline \multirow[t]{4}{*}{ cyclohexane } & $\mathrm{N}: 435$ & $420 \mathrm{~nm}(\tau=1.10)$ \\
\hline & $\mathrm{T}: 550$ & $530 \mathrm{~nm}\left[\tau_{1}=0.06(-0.48), \tau_{2}=0.23(0.22), \tau_{3}=1061(0.30)\right]$ \\
\hline & $(0.13)$ & $570 \mathrm{~nm}\left[\tau_{1}=1.22(-0.41), \tau_{2}=1061(0.59)\right]$ \\
\hline & & $620 \mathrm{~nm}\left[\tau_{1}=1.20(-0.43), \tau_{2}=1061(0.57)\right]$ \\
\hline \multirow[t]{4}{*}{ benzene } & $\mathrm{N}: 433$ & $450 \mathrm{~nm}(\tau=1.00)$ \\
\hline & T: 590 & $570 \mathrm{~nm}\left[\tau_{1}=1.16(-0.12), \tau_{2}=1.50(0.69), \tau_{3}=566(0.19)\right]$ \\
\hline & $(0.033)$ & $630 \mathrm{~nm}\left[\tau_{1}=1.00(-0.53), \tau_{2}=1.60(0.20), \tau_{3}=566(0.27)\right]$ \\
\hline & & $690 \mathrm{~nm}\left[\tau_{1}=0.80(-0.16), \tau_{2}=1.60(-0.29), \tau_{3}=566(0.55)\right.$ \\
\hline \multirow[t]{4}{*}{ dichloromethane } & $\mathrm{N}: 440$ & $450 \mathrm{~nm}\left[\tau_{1}=0.60(0.93), \tau_{2}=6.00(0.07)\right]$ \\
\hline & $\mathrm{T}: 648$ & $610 \mathrm{~nm}\left[\tau_{1}=0.54(-0.43), \tau_{2}=0.90(0.39), \tau_{3}=18.2(0.18)\right]$ \\
\hline & $(0.0018)$ & $670 \mathrm{~nm}\left[\tau_{1}=0.43(-0.40), \tau_{2}=1.30(0.33), \tau_{3}=19.4(0.27)\right]$ \\
\hline & & $710 \mathrm{~nm}\left[\tau_{1}=0.67(-0.48), \tau_{2}=1.40(0.26), \tau_{3}=19.0(0.26)\right]$ \\
\hline \multirow[t]{4}{*}{ acetonitrile } & $\mathrm{N}: 443$ & $460 \mathrm{~nm}(\tau=0.31)$ \\
\hline & $\mathrm{T}: 750$ & $700 \mathrm{~nm}\left[\tau_{1}=0.53(0.61), \tau_{2}=3.2(0.39)\right]$ \\
\hline & $(0.0006)$ & $730 \mathrm{~nm}\left[\tau_{1}=0.70(0.25), \tau_{2}=2.9(0.75)\right]$ \\
\hline & & $760 \mathrm{~nm}\left[\tau_{1}=0.80(0.08), \tau_{2}=2.8(0.92)\right]$ \\
\hline \multicolumn{3}{|l|}{ diCN-HBT } \\
\hline \multirow[t]{2}{*}{ cyclohexane } & $\mathrm{N}:-$ & $480 \mathrm{~nm}(\tau=0.05)$ \\
\hline & $\begin{array}{l}\text { T: } 575 \\
(0.05)\end{array}$ & $580 \mathrm{~nm}\left[\tau_{1}=0.07(-0.10), \tau_{2}=995(0.90)\right]$ \\
\hline \multirow[t]{4}{*}{ dichloromethane } & $\mathrm{N}: 453$ & $480 \mathrm{~nm}(\tau=0.06)$ \\
\hline & $\mathrm{T}: 666$ & $580 \mathrm{~nm}\left[\tau_{1}=0.06(-0.40), \tau_{2}=1.00(0.56), \tau_{3}=85(0.04)\right]$ \\
\hline & $(0.0042)$ & $630 \mathrm{~nm}\left[\tau_{1}=0.15(-0.36), \tau_{2}=1.20(0.38), \tau_{3}=85(0.26)\right]$ \\
\hline & & $680 \mathrm{~nm}\left[\tau_{1}=0.12(-0.31), \tau_{2}=1.20(0.35), \tau_{3}=85(0.34)\right]$ \\
\hline \multirow[t]{4}{*}{ acetonitrile } & $\mathrm{N}: 452$ & $480 \mathrm{~nm}(\tau=0.13)$ \\
\hline & T: 730 & $680 \mathrm{~nm}\left[\tau_{1}=0.05(-0.31), \tau_{2}=0.59(0.54), \tau_{3}=6.5(0.15)\right]$ \\
\hline & $(0.0006)$ & $720 \mathrm{~nm}\left[\tau_{1}=0.08(-0.23), \tau_{2}=0.72(0.58), \tau_{3}=7.6(0.19)\right]$ \\
\hline & & $760 \mathrm{~nm}\left[\tau_{1}=0.11(-0.11), \tau_{2}=0.87(0.62), \tau_{3}=8.5(0.27)\right]$ \\
\hline
\end{tabular}

${ }^{a}$ The experimental error for the fitted time constant and quantum yield is less than $\sim 20 \%$. ${ }^{b}$ Data in the parentheses are the fitted pre-exponential factors.

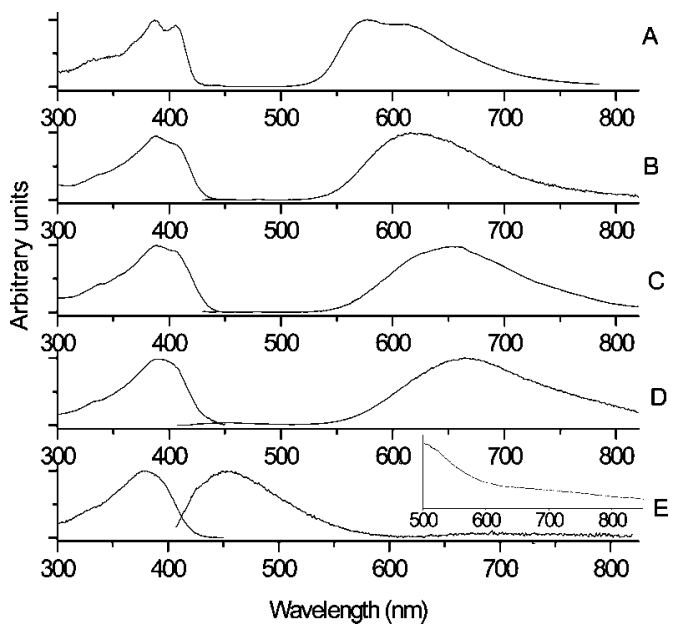

Figure 2. Static absorption and fluorescence spectra of diCN-HBT at $298 \mathrm{~K}$ in (A) cyclohexane, (B) benzene, (C) chloroform, (D) dichloromethane, and (E) acetonitrile; the inserted small graph was generated using ICCD as a detector.

comparison to those molecules previously designed, diCN-HBO and diCN-HBT seem to be ideal systems with which to probe the ESPT/ESCT coupling reaction, possibly free from interference of solvent relaxation.

To investigate detailed ESPT dynamics, femtosecond timeresolved fluorescence of diCN-HBO and diCN-HBT was monitored at both enol and keto emission bands in five different solvents. The excitation wavelength was tuned to the $0-0$ onset of the $S_{0} \rightarrow S_{1}$ absorption at $\sim 400 \mathrm{~nm}$ to minimize the vibronic relaxation process, and the excitation power was $<20 \mathrm{~mW}$ to avoid any possible photodecomposition processes. The timedependent sum frequency signal and the best theoretical fitting

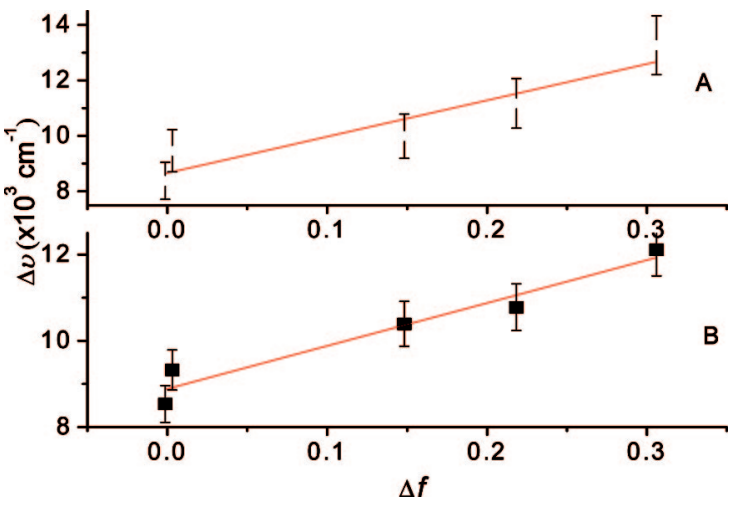

Figure 3. Lippert plot of Stokes shift of keto emission vs orientation polarizability $(\Delta f)$ of $(\mathrm{A})$ diCN-HBO and $(\mathrm{B})$ diCN-HBT $(\Delta f$ : cyclohexane, -0.0014 ; benzene, 0.0030; chloroform, 0.1482; dichloromethane, 0.2183; and acetonitrile, 0.3060).

of diCN-HBO are depicted in Figures 4-7. Detailed fitting parameters for the relaxation decay rates are listed in Table 1. The relaxation dynamics clearly show that the fluorescence temporal behavior varies drastically with changes of the monitored fluorescence wavelength. In cyclohexane, the upconverted fluorescence signal at the very blue side of, for example, $420 \mathrm{~nm}$, ascribed to the steady-state enol emission, consists of a system response limited ( $<150 \mathrm{fs}$ ) rise component, a fast but clearly resolvable decay of $1.10 \pm 0.15 \mathrm{ps}$. As shown in Figure 4, no long population decay component can be resolved in this region. Note that monitoring at further blue regions was not performed due to the interference of the solvent Raman scattering. The 1.1 ps decay component eventually disappears when the emission wavelength is monitored at the keto emission of, for example, $570 \mathrm{~nm}$. Instead, a finite rise 


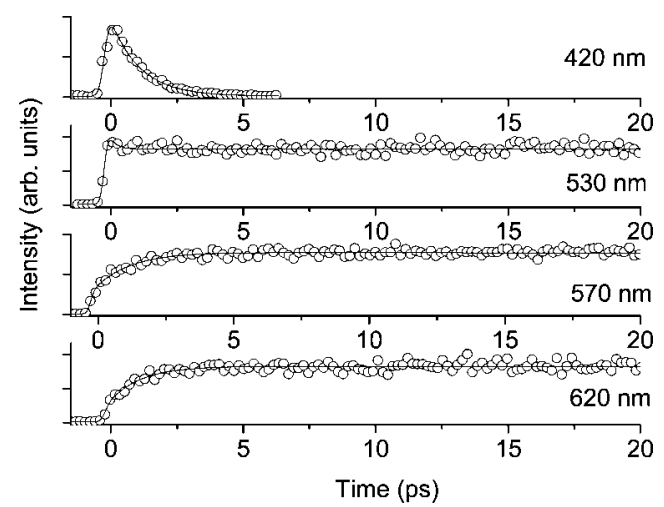

Figure 4. Time-resolved sum frequency signal of fluorescence and gate pulse $(780 \mathrm{~nm})$ for diCN-HBO in cyclohexane. The solid lines express the best exponential fitting curves.

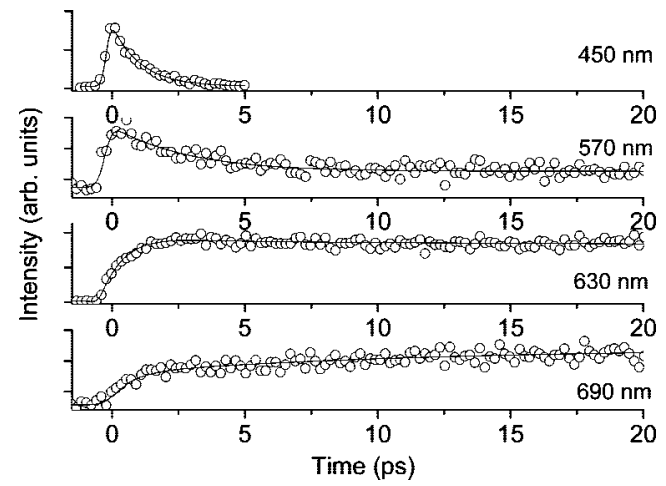

Figure 5. Time-resolved sum frequency signal of fluorescence and gate pulse $(780 \mathrm{~nm})$ for diCN-HBO in benzene. The solid lines express the best exponential fitting curves.

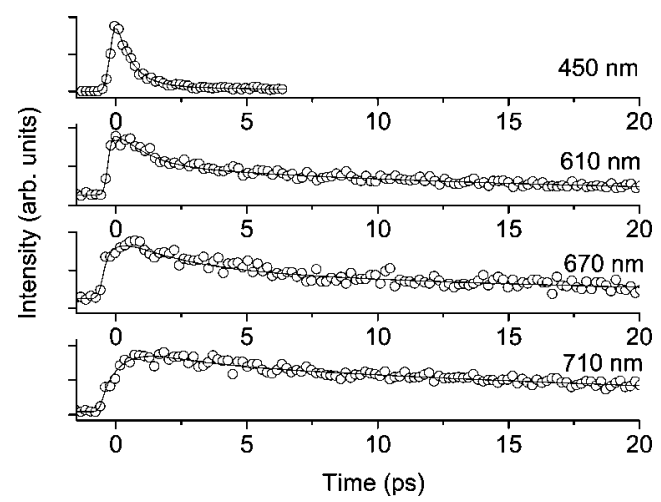

Figure 6. Time-resolved sum frequency signal of fluorescence and gate pulse $(780 \mathrm{~nm})$ for diCN-HBO in dichloromethane. The solid lines express the best exponential fitting curves.

component of $1.2 \pm 0.16$ ps was resolved, followed by a long population decay component that remained nearly constant within the monitoring time range. The long population decay was further resolved to be $1.1 \mathrm{~ns}$ by time-correlated single photon counting technique. The risetime $(1.2 \mathrm{ps})$ of the keto tautomer emission, within experimental error, correlates very well with the fast decay (1.1 ps) of the enol emission, suggesting a precursor-successor type of relationship between enol and keto tautomer species via ESPT reaction. Its rate constant was determined to be $1.10 \pm 0.15$ ps.

Figures 5-7 depict the time-resolved traces of diCN-HBO in other polar, aprotic solvents. For all cases, upon monitoring at the enol emission, its relaxation dynamics is always composed of an ultrafast rise, together with a fast decay component. The decay rate constant was resolved to be $1.00 \pm 0.13$ ps in

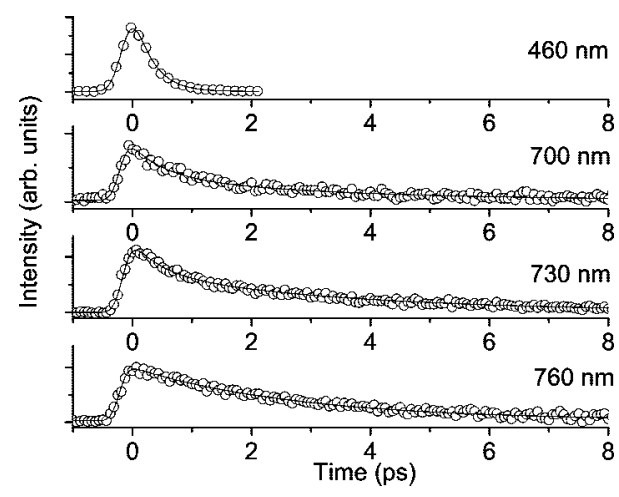

Figure 7. Time-resolved sum frequency signal of fluorescence and gate pulse $(780 \mathrm{~nm})$ for diCN-HBO in acetonitrile. The solid lines express the best exponential fitting curves.

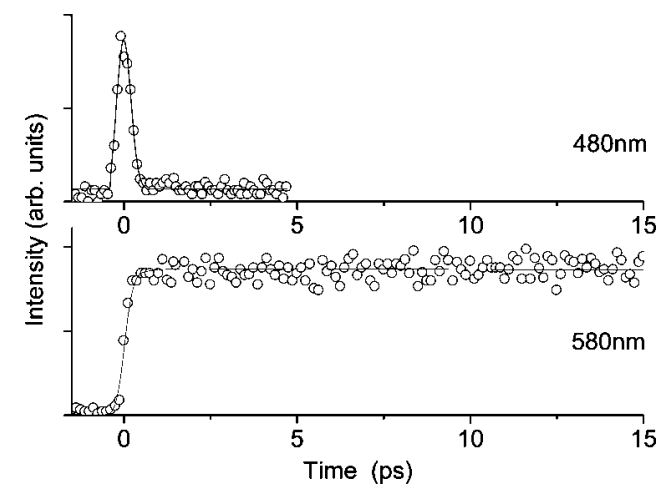

Figure 8. Time-resolved sum frequency signal of fluorescence and gate pulse $(800 \mathrm{~nm})$ for diCN-HBT in cyclohexane. The solid lines express the best exponential fitting curves.

benzene, $0.60 \pm 0.05 \mathrm{ps}$ in $\mathrm{CH}_{2} \mathrm{Cl}_{2}$, and $0.31 \pm 0.03 \mathrm{ps}$ in $\mathrm{CH}_{3} \mathrm{CN}$, respectively, values that reveal a tendency that increasing the solvent polarity renders an increase of the rate of ESPT. In polar solvents, the keto emission shows significantly different relaxation dynamics as compared to that in cyclohexane. As shown in Figures 5-7 and Table 1, the dynamics of relaxation apparently require three exponential terms to achieve good convoluted fits: (i) a resolvable rise component with a time constant of $0.5-1.2 \mathrm{ps}$, which, within experimental error, correlates well with the fast decay component monitored at enol emission; (ii) a solvent-dependent, fast decay component of, for example, $\sim 1.6 \mathrm{ps}$ in benzene, $\sim 1.3 \mathrm{ps}$ in $\mathrm{CH}_{2} \mathrm{Cl}_{2}$, and $\sim 0.7$ ps in $\mathrm{CH}_{3} \mathrm{CN}$ upon monitoring at the blue side of the keto emission. Upon increasing the monitored wavelength in the region of the keto emission, this fast decay component gradually becomes the rise component, especially toward the red edge of the keto emission. Note that the 0.3 ps rise component is irresolvable in $\mathrm{CH}_{3} \mathrm{CN}$ due to the very similar time constant, as compared with the $\sim 0.7$ ps decay component; and (iii) a much slower population decay component that was resolved to be few hundred ps to ns, depending on solvent polarity. As the solvent polarity increases, the corresponding population decay time of the keto emission decreases (see Table 1).

As for diCN-HBT, upon monitoring at enol emission of, for example, $480 \mathrm{~nm}$ in cyclohexane, the decay time ( $<150 \mathrm{fs}$ ) was beyond the system response of $150 \mathrm{fs}$, while the temporal resolution at, for example, $580 \mathrm{~nm}$, ascribed to the keto emission, consists of a response limited ( $<150 \mathrm{fs}$ ) rise component and a much longer population decay component of $\sim 1.0 \mathrm{~ns}$ resolved by single photon counting technique (Figure 8). Similar to its parent ESPT molecule HBT, ${ }^{13 b}$ the results conclude an ultrafast and perhaps barrierless ESPT for diCN-HBT in nonpolar 


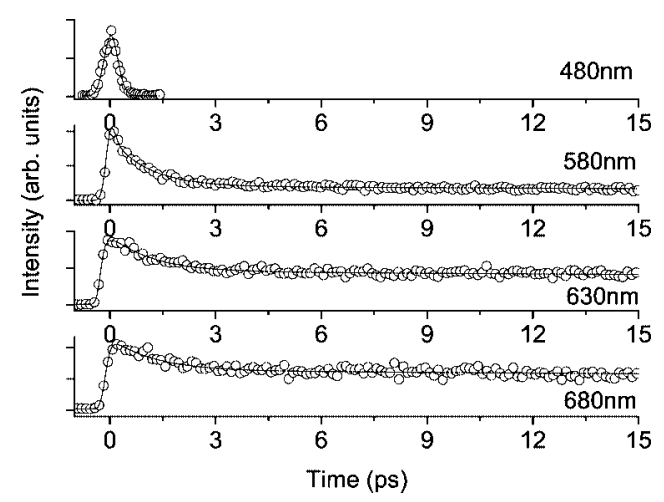

Figure 9. Time-resolved sum frequency signal of fluorescence and gate pulse $(800 \mathrm{~nm})$ for diCN-HBT in dichloromethane. The solid lines express the best exponential fitting curves.

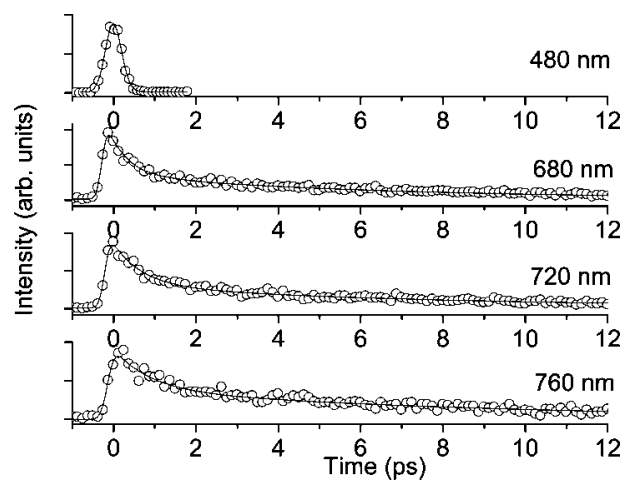

Figure 10. Time-resolved sum frequency signal of fluorescence and gate pulse $(800 \mathrm{~nm})$ for diCN-HBT in acetonitrile. The solid lines express the best exponential fitting curves.

solvents. In polar, protic solvents, the early relaxation dynamics of diCN-HBT are also different from that of diCN-HBO. Typical relaxation dynamics of diCN-HBT in $\mathrm{CH}_{2} \mathrm{Cl}_{2}$ and $\mathrm{CH}_{3} \mathrm{CN}$ are depicted in Figures 9 and 10, respectively. Detailed fitting parameters of early time relaxation dynamics as well as population decay rates in various solvents are listed in Table 1. In contrast to the finite, resolvable decay dynamics of the diCNHBO enol emission, the upconverted enol emission signal for diCN-HBT could only be fitted by a system-response limited decay time $(<150 \mathrm{fs})$ in all solvents $\left(\mathrm{C}_{6} \mathrm{H}_{12}, \mathrm{CH}_{2} \mathrm{Cl}_{2}\right.$, and $\mathrm{CH}_{3} \mathrm{CN}$ ) studied. As for the keto emission band, it turned out that the experimental results were composed of three distinct components: (i) a system response limited rise component $(<150$ fs); (ii) upon monitoring at the blue side of the keto emission, a fast but resolvable decay component, which was fitted to be $0.6-1.2 \mathrm{ps}$, depending on the solvent (see Table 1). Such a decay component gradually disappeared and became a rise component at the red tail of the emission; and (iii) a much slower population decay component that was resolved to be 995,85 , and $\sim 8$ ps in $\mathrm{C}_{6} \mathrm{H}_{12}, \mathrm{CH}_{2} \mathrm{Cl}_{2}$, and $\mathrm{CH}_{3} \mathrm{CN}$, respectively.

In brief, the relaxation dynamics for both diCN-HBO and diCN-HBT can be generally described by three types of rate constants: (i) rate of ESPT, which dominates the decay of the enol emission; (ii) rate of solvent relaxation in the keto form; and (iii) population decay rate of the keto form. Furthermore, in the same solvent, the rate of ESPT in diCN-HBT seems to be always faster than that in diCN-HBO. For both diCN-HBO and diCN-HBT, upon increasing solvent polarity, the rate of ESPT increases and the population decay time of the proton transfer keto form decreases. It is also noted that the decrease of population decay time correlates well with respect to the
SCHEME 6: Proposed ESPT/ESCT Reaction/Relaxation Dynamics Using diCN-HBO as a Model ${ }^{a}$

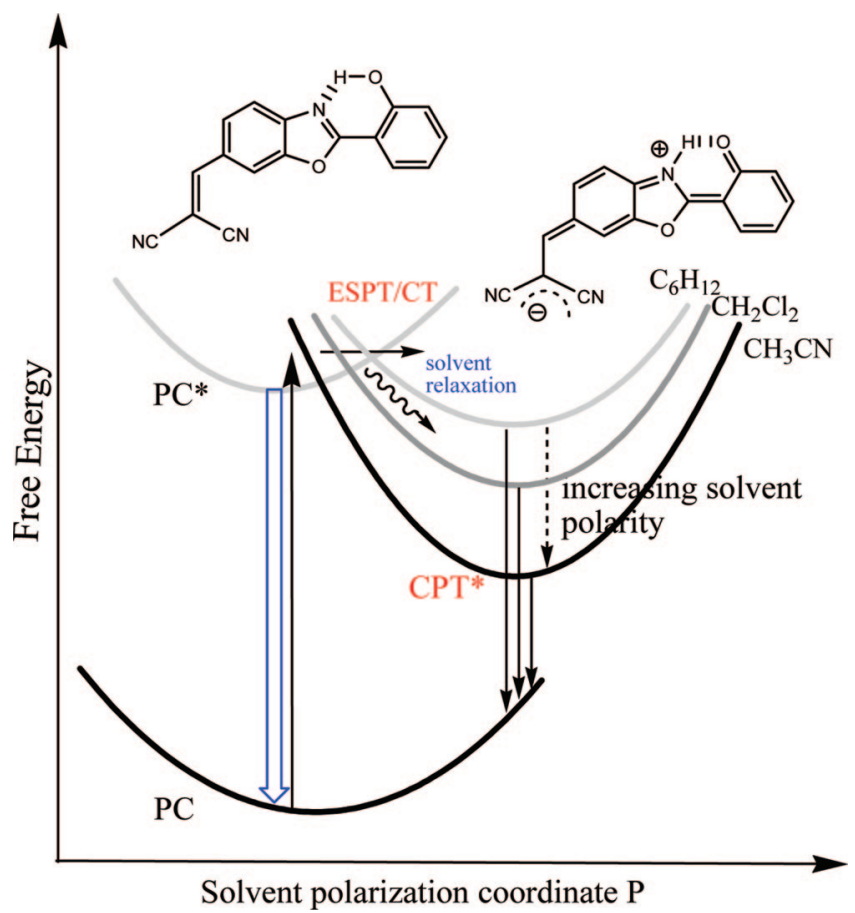

${ }^{a}$ Note that this assumption of a parabolic potential as a function of solvent polarity is a simplistic model and is valid only if any specific solute/solvent interaction is neglected.

reduction of the keto emission yield observed in the steadystate approach.

\section{Discussion}

In light of the steady state and dynamics results above, the overall reaction dynamics can be well-described by case B, incorporating ESPT coupled with ESCT process (see Scheme 1). An essential requirement to rationalize the above relaxation processes of diCN-HBO (diCN-HBT) lies in the fact that PC* has similar dipolar properties with respect to $\mathrm{PC}$, while its proton transfer tautomer, denoted by PT* (see Schemes 1, 4, and 6), should concomitantly associate with charge transfer (see Scheme), forming a proton/charge transfer species denoted by CPT* CPT* possesses a large degree of charge transfer character and is expected to have a dipolar vector quite different from that of $\mathrm{PC}^{*}$. Accordingly, the overall $\mathrm{PC}^{*} \rightarrow \mathrm{CPT}^{*}$ reaction dynamics for diCN-HBO (or diCN-HBT) can be described by a twodimensional model incorporating proton transfer reaction coordinate and solvent polarization coordinate. In Scheme 6, only the two lowest energy proton transfer diabatic surfaces are shown for the reactant (PC*) and product (CPT*) and labeled according to the dominant diabatic states; $P C_{\mathrm{eq}}{ }^{*}$ and $C P T_{\mathrm{eq}}{ }^{*}$ denote the equilibrium solvent configurations of $\mathrm{PC}^{*}$ and $\mathrm{CPT}^{*}$. Note that a parabolic potential energy surface as a function of solvent polarity is adopted in Scheme 6. This is justified based on the model that solvent polarity effect is considered to be a harmonic type of interaction. The curvature of potential surface for $\mathrm{CPT}^{*}$, possessing a larger dipole moment, is much steeper than that of PC*. Accordingly, the minimum (equilibrium) energy for CPT* is solvent-dependent and should be decreased as the solvent polarity is increased, whereas that of $\mathrm{PC}^{*}$ is assumed to be negligible and is thus not depicted in Scheme 6 .

In polar solvents, because of the drastic changes of the dipole moment upon executing the $\mathrm{PC}^{*} \rightarrow \mathrm{CPT} *$ reaction, the reaction 
dynamics are expected to be incorporated with solvent reorganization; consequently, a solvent polarity-induced barrier is expected, which should channel into the reaction. This regime of ESPT coupled ESCT process may be treated as the reactions of electronically adiabatic proton transfer and electronically nonadiabatic electron transfer. ${ }^{14}$ For both diCN-HBO and diCNHBT, such a charge transfer process takes place from the $\pi^{*}$ electron delocalization and should proceed simultaneously at every moment that ESPT takes place. The overall reaction pattern is thus analogous to Marcus theory for the photoinduced electron transfer, and the corresponding rate may be expressed as $^{14 \mathrm{~b}}$

$$
\begin{aligned}
k_{p t}=\frac{C_{00}^{2}}{\hbar} \sqrt{\frac{\pi}{E_{\mathrm{s}} R T}} \exp \left[-\frac{\Delta G^{+}}{R T}\right]= \\
\qquad \frac{C_{00}^{2} \sqrt{\frac{\pi}{E_{\mathrm{s}} R}} \exp \left[-\frac{\left(\Delta G_{\mathrm{RXN}}+E_{\mathrm{s}}\right)^{2}}{R T\left(4 E_{\mathrm{s}}\right)}\right]}{}
\end{aligned}
$$

where $C_{00}^{2}$ represents the proton coupling's quantum average over the vibrational modes associated with the proton motion, $E_{\mathrm{S}}$ is the solvent reorganization free energy, and $\Delta G^{+}$and $\Delta G_{\mathrm{RXN}}$ denote the solvent-induced barrier and the reaction free energy, respectively. Unlike the electron transfer reaction, $\Delta G_{\mathrm{RXN}}$ may not be accessible due to the perhaps nonexistent proton transfer species in the ground state. Because the current femto system could not perform temperature-dependent fluorescence upconversion measurement, a quantitative deduction of a solvent-induced barrier is also not feasible. Nevertheless, as for a qualitative approach, the trend of the increase in the overall reaction rate in $\mathrm{diCN}-\mathrm{HBO}$ upon an increase in the solvent polarity (vide supra) can be rationalized by the decrease of the solvent-induced barrier upon the increase in the solvent polarity, that is, a model within the normal Marcus electron transfer region. ${ }^{15}$ Furthermore, comparing that in diCN-HBO, the faster rate of ESPT in diCN-HBT can tentatively be explained by the lesser changes of dipole moment (vide supra) and hence the reduction of the solvent-induced barrier.

Upon forming $\mathrm{CPT}^{*}$, the unfavorable polarization configuration is subsequently subjected to a rapid solvent relaxation/ reorientation, that is, component ii with a time scale of $0.6-1.6$ ps depending on the type of solvents, to reach an energetically more favorable solvated configuration. After reaching the equilibrium state $C P T_{\mathrm{eq}}{ }^{*}$, population decay takes place (component iii). Note that the rate of ESPT/ESCT for diCN-HBO (diCN-HBT) in $\mathrm{CH}_{3} \mathrm{CN}$ is faster than that in, for example, $\mathrm{CH}_{2} \mathrm{Cl}_{2}$, while the associated keto emission is much weaker. For the charge transfer emission, this result is not uncommon, especially in strong polar solvents like $\mathrm{CH}_{3} \mathrm{CN}$, where the ultrafast radiationless transition is generally observed. ${ }^{16}$ Dramatic polarity effects for the nonradiative charge transfer state (electron separated form) $\rightarrow S_{0}$ (neutral form) back electron transfer have been reported in several electron transfer systems. ${ }^{17}$ As the zeroorder gap between $\mathrm{PC}^{*}$ and $\mathrm{CPT}^{*}$ increases with increases in the solvent polarity, the radiative decay rate of CPT* in this study decreases accordingly due to the reduction in $\mathrm{PC} * / \mathrm{CPT}^{*}$ interaction and, hence, a larger fraction of the forbidden transition. In addition, the smaller energy gap of the CPT* emission in higher polar solvent normally associates with faster radiationless deactivation, an operation of the energy gap law. ${ }^{18}$ These combinations explain the extremely weak keto emission for both diCN-HBO and diCN-HBT in $\mathrm{CH}_{3} \mathrm{CN}$.

Another intriguing issue lies in the finite ESPT rate of $1.1 \pm$ 0.15 ps for diCN-HBO measured in cyclohexane. The results are in sharp contrast to the $150 \mathrm{fs}$ of ESPT for the parent compound $\mathrm{HBO} .{ }^{12 \mathrm{c}}$ On one hand, assuming that the dynamics of ESIPT in diCN-HBO are free from solvent perturbation in cyclohexane, it may imply that the charge transfer property in diCN-HBO leads to different distribution of the charge density from that of $\mathrm{HBO}$ such that the driving force (photoacidity and basicity and so forth) for ESPT is appreciably reduced in diCNHBO. However, if this were the case, a similar small tunneling term $C_{00}^{2}$ (see eq 1 ), and hence a slower overall reaction rate, would be expected in polar solvents, which is opposite to the results shown in Table 1. Alternatively, the relatively slow proton transfer rate in cyclohexane indicates that solvent induced polarization may still play a role in the ESPT/ESCT coupled reaction in cyclohexane. In nonpolar solvents, although the parabolic potential energy surface along the solvent coordinate is shallow due to the much less solvent polarization stabilization, the far separated equilibrium polarization between normal and tautomer, as in the case of diCN-HBO, may still introduce appreciable barrier, that is, high intersection point (see Scheme 6). It is also worthy to note that a dynamic polarization model in nonpolar solvents has recently been proposed by Hamaguchi and co-workers. ${ }^{19}$ Because of the large dipolar change between $\mathrm{PC}^{*}$ and $\mathrm{CPT}^{*}$ in the case of diCN-HBO, the induced dipole/ dipole interaction is considered to be non-negligible, inducing an appreciable barrier in the ESPT/ESCT coupled reaction.

\section{Conclusion}

In summary, we report on the excitation behavior of the proton-coupled charge transfer reaction for diCN-HBO and diCN-HBT. The results demonstrate an example of excited-state intramolecular proton transfer simultaneously coupled with electron transfer process. Accordingly, dual emission was observed, and the proton transfer emission peak wavelength was drastically dependent on the solvent polarity. The solvent longrange polarization interactions may induce a barrier that channels into the proton transfer reaction. The overall reaction dynamics can be described by a mechanism incorporating both solvent polarization and proton transfer reaction coordinates. As the solvent polarity increases, its induced barrier reduces, and the overall rate of ESPT decreases, the results of which can be qualitatively rationalized under the basis of electron transfer theory coupled with the proton tunnelling effect. The results and discussion presented in this study open up an experimental prototype to probe nuclear motion (proton transfer) coupled with the solvent polarity effect.

Acknowledgment. We thank the National Science Council (Grant no. 99-1989-2004) for the financial support.

\section{References and Notes}

(1) (a) Elsaesser, T. H.; Bakker, H. J. Ultrafast Hydrogen Bonding Dynamics and Proton Transfer Processes in the Condensed Phase; Kluwer Academic Publishers: Boston, 2002. (b) Waluk, J. Conformational Analysis of Molecules in Excited States; Waluk, J., Ed.; Wiley-VCH: New York, 2000. (c) Müller, A.; Ratajczak H.; Junge, W.; Diemann, E. Studies in Physical and Theoretical Chemistry: Electron and Proton Transfer in Chemistry and Biology; Elsevier: Amsterdam and New York, 1992; Vol. 78.

(2) (a) Waluk, J. Acc. Chem. Res. 2003, 36, 832. (b) Tanner, C.; Manca, C.; Leutwyler, S. Science 2003, 302, 1736. (c) Tolbert, L. M.; Solntsev, K. M. Acc. Chem. Res. 2003, 35, 19. (d) Scheiner, S. J. Phys. Chem. A 2000, 104, 5898. (e) Paterson, M. J.; Robb, M. A.; Blancafort, L.; DeBellis, A. D. J. Am. Chem. Soc. 2004, 126, 2912. (f) Lochbrunner, S.; Wurzer, A. J.; Riedle, E. J. Phys. Chem. A 2003, 107, 10580. (g) de Vivie-Riedle, R.; De Waele, V.; Kurtz, L.; Riedle, E. J. Phys. Chem. A 2003, 107, 10591. (h) Cheng, C.-C.; Chang, C.-P.; Yu, W.-S.; Hung, F.-T.; Liu, Y.-I.; Wu, G.-R.; Chou, P.-T. J. Phys. Chem. A 2003, 107, 1459. (i) Lukeman, M.; Wan, P. J. Am. Chem. Soc. 2003, 125, 1164. (j) Yu, W.-S.; Cheng, C.-C.; Cheng, Y.-M.; Wu, P.-C.; Song, Y.-H.; Chi, Y.; Chou, P.-T. J. Am. Chem. 
Soc. 2003, 125, 10800. (k) Rodembusch, F. S.; Leusin, F. P.; Campo, L. F.; Stefani, V. J. Lumin. 2007, 126, 728.

(3) (a) Gormin, D.; Kasha, M. Chem. Phys. Lett. 1988, 153, 574. (b)

Heldt, J.; Gormin, D.; Kasha, M. Chem. Phys. 1989, 136, 321.

(4) (a) Shynkar, V. V.; Mély, Y.; Duportail, G.; Píemont, E.; Klymchenko, A. S.; Demchenko, A. P. J. Phys. Chem. A 2003, 107, 9522. (b) Chou, P.-T.; Pu, S.-C.; Cheng, Y.-M.; Yu, W.-S.; Yu, Y.-C.; Hung, F.-T.; Hu, W.-P. J. Phys. Chem. A 2005, 109, 3777. (c) Parsapour, F.; Kelley, D. F. J. Phys. Chem. 1996, 100, 2791. (d) Chou, P.-T.; Martinez, M. L.; Clements, J. H. J. Phys. Chem. 1993, 97, 2618. (e) Roshal, A. D.; Organero, J. A.; Douhal, A. Chem. Phys. Lett. 2003, 379, 53. (f) Ameer-Beg, S.; Ormson, S. M.; Poteau, X.; Brown, R. G.; Foggi, P.; Bussotti, L.; Neuwahl, F. V. R. J. Phys. Chem. A 2004, 108, 6938.

(5) (a) Chou, P.-T.; Martinez, M. L.; Clements, J. H. Chem. Phys. Lett. 1993, 204, 395. (b) Swinney, T. C.; Kelley, D. F. J. Chem. Phys. 1993, 99 211. (c) Parsapour, F.; Kelley, D. F. J. Phys. Chem. 1996, 100, 2791. (d) Ormson, S. M.; Brown, R. G.; Vollmer, F.; Rettig, W. J. Photochem. Photobiol. 1994, 81, 65. (e) Chou, P.-T.; Huang, C.-H.; Pu, S.-C.; Cheng, Y.-M.; Liu, Y.-H.; Wang, Y.; Chen, C.-T. J. Phys. Chem. A 2004, 108, 6452. (f) Cheng, Y.-M.; Pu, S.-C.; Yu, Y.-C.; Chou, P.-T.; Huang, C.-H.; Chen, C.-T.; Li, T.-H.; Hu, W.-P. J. Phys. Chem. A 2005, 109, 11696.

(6) Cheng, Y.-M.; Pu, S.-C.; Hsu, C.-J.; Lai, C.-H.; Chou, P.-T ChemPhysChem 2006, 7, 1372.

(7) Chou, P.-T; Yu, W-S. Cheng, Y.-M ; Pu, S.-C.; Yu, Y.-C.; Lin, Y.-C.; Huang, C.-H.; Chen, C.-T. J. Phys. Chem. A 2004, 108, 6487.

(8) (a) Napper, A. M.; Head, N. J.; Oliver, A. M.; Shephard, M. J.; Paddon-Row, M. N.; Read, I.; Waldeck, D. H. J. Am. Chem. Soc. 2002 124, 10171. (b) Shephard, M. J.; Paddon-Row, M. N.; Jordan, K. D. Chem Phys. 1993, 176, 289. (c) Paddon-Row, M. N.; Shephard, M. J. J. Am. Chem. Soc. 1997, 119, 5355. (d) Lai, C.-H.; Li, E. Y.; Chen, K.-Y.; Chow, T. J.; Chou, P. T. J. Chem. Theory Comput. 2006, 2, 1078.
(9) (a) Kiefer, P. M.; Hynes, J. T. J. Phys. Chem. A 2002, 106, 1834. (b) Kiefer, P. M.; Hynes, J. T. J. Phys. Chem. A 2002, 107, 9022.

(10) Seo, J.; Kim, S.; Park, S. Y. J. Am. Chem. Soc. 2004, 126, 11154.

(11) Chedekel, M. R.; Sharp, D. E.; Jeffery, G. A. Synth. Commun. 1980, 167.

(12) (a) Arthen-Engeland, T.; Bultmann, T.; Ernsting, N. P.; Rodriguez, M. A.; Thiel, W. Chem. Phys. 1992, 163, 43. (b) Abou-Zied, O. K.; Jimenez, R.; Thompson, E. H. Z.; Millar, D. P.; Romesberg, F. E. J. Phys. Chem. A 2002, 106, 3665. (c) Wang, H.; Zhang, H.; Abou-Zied, O. K.; Yu, C.; Romesberg, F. E.; Glasbeek, M. Chem. Phys. Lett. 2003, 367, 599.

(13) (a) Becker, R. S.; Lenoble, C.; Zein, A. J. Phys. Chem. 1987, 91, 3509. (b) Frey, W.; Laermer, F.; Elsaesser, T. J. Phys. Chem. 1991, 95 , 10391.

(14) (a) Soudackov, A. V.; Hammes-Schiffer, S. J. Chem. Phys. 1999, 111, 4672. (b) Soudackov, A. V.; Hammes-Schiffer, S. J. Chem. Phys. 2000, 113, 2385. (c) Hammes-Schiffer, S. Acc. Chem. Res. 2001, 34, 273.

(15) (a) Marcus, R. A. J. Chem. Phys. 1965, 43, 379. (b) Marcus, R. A. Annu. Rev. Phys. Chem. 1964, 15, 155. (c) Marcus, R. A. J. Chem. Phys. 1965, 43, 679. (d) Marcus, R. A. Rev. Mod. Phys. 1993, 65, 599.

(16) Chou, P. T.; Chang, C. P.; Clements, J. H.; Kuo, M. S. J. Fluoresc. $1995,5,369$.

(17) (a) Hopfield, J. J. Protein Structure: Molecular and Electronic Reactivity; Springer: New York, 1987. (b) Joran, A. D.; Leland, B. A.; Felker, P. M.; Zewail, A. H.; Hopfield, J. J.; Dervan, P. B. Nature 1987, $327,508$.

(18) Siebrand, W. J. Chem. Phys. 1967, 47, 2411.

(19) Iwata, K.; Ozawa, R.; Hamaguchi, H. J. Phys. Chem. A 2002, 106, 3614

JP804216U 